\title{
Being physically active through chronic illness: life experiences of people with arthritis
}

\section{Emily R. Hunt \& Anthony Papathomas}

To cite this article: Emily R. Hunt \& Anthony Papathomas (2020) Being physically active through chronic illness: life experiences of people with arthritis, Qualitative Research in Sport, Exercise and Health, 12:2, 242-255, DOI: 10.1080/2159676X.2019.1601637

To link to this article: https://doi.org/10.1080/2159676X.2019.1601637

$$
\begin{aligned}
& \text { (c) } 2019 \text { The Author(s). Published by Informa } \\
& \text { UK Limited, trading as Taylor \& Francis } \\
& \text { Group. }
\end{aligned}
$$

\section{曲 Published online: 09 Apr 2019.}

Submit your article to this journal 지

Џ Article views: 987

Q View related articles $\sqsubset$

View Crossmark data $₫$ 


\title{
Being physically active through chronic illness: life experiences of people with arthritis
}

\author{
Emily R. Hunt ${ }^{\mathrm{a}, \mathrm{b}}$ and Anthony Papathomas ${ }^{\mathrm{b}}$
}

${ }^{\text {aC College of Health and Life Sciences, Brunel University London, London, UK; }{ }^{b} S c h o o l ~ o f ~ S p o r t, ~ E x e r c i s e ~ a n d ~ H e a l t h ~}$ Sciences, Loughborough University, Loughborough, UK

\begin{abstract}
Despite the therapeutic potential of exercise for people with arthritis, they are considerably less active than the general population. To explain this phenomenon, research rarely moves beyond descriptive accounts of exercise barriers and facilitators. Although a useful start point, such studies list decontextualised factors without situating these within the wider experience of living with chronic illness. As such, we know little about what physical activity means to people with arthritis and the personal circumstances that support exercise participation or otherwise. To address this gap, we used life-story interviews to explore participants' broad experiences of exercise and arthritis. Interviews with 21 people (6 male, 15 female) aged between 24 and 79 years ( $M=57.7$ years) and diagnosed with arthritis for between 6 months and 35 years ( $M=12.7$ years) yielded over $35 \mathrm{~h}$ of data, with each interview lasting between 55-160 min. Through an inductive thematic analysis of the data, we constructed three themes; making sense of arthritis, adapting and enjoying exercise, and exercise as medicine. Participants constructed both illness and exercise differently and this held consequences for their exercise experience. Barriers to exercise became more surmountable once participants had achieved a satisfactory understanding of arthritis and its consequences. Physical activity promotion in clinical populations might benefit from supporting adaptation to illness more generally as opposed to an exclusive exercise focus.
\end{abstract}

ARTICLE HISTORY

Received 27 July 2018

Accepted 26 March 2019

\section{KEYWORDS}

Exercise; rheumatology; osteoarthritis; disability; lifestory

\section{Introduction}

Arthritis is a chronic condition characterised by the inflammation and deterioration of the joints. There are many types of arthritis that fall within two main categories: inflammatory arthritis (e.g. Rheumatoid Arthritis, Psoriatic Arthritis) and degenerative arthritis (e.g. Osteoarthritis) (Hughes 2009). The different types of arthritis can vary in severity and symptoms, but most commonly people with arthritis can experience pain, stiffness, fatigue and flu-like symptoms. In addition to symptoms, arthritis can have a broader negative impact on physical, psychological and social health. Physically, arthritis is one of the leading causes of disability (Vos et al. 2015) and people with arthritis can experience comorbidities such as cardiovascular disease, osteoporosis, and infections (Michaud and Wolfe 2007). Psychologically, having arthritis has been associated with anxiety and the on-set of depressive symptoms (Bookwala, Harralson, and Parmelee 2003; Zyrianova et al. 2011). Socially, people with arthritis are reported to have difficulties maintaining 
social activities, becoming more isolated from society (Gettings 2010). Thus, arthritis can have a large impact on the quality of life for the individual (Bolen et al. 2010; Theis et al. 2007).

Physical activity has been shown to have a positive impact on the physical and mental health of people with arthritis. By participating in appropriate low-impact physical activity, individuals can reduce pain and improve quality of life, daily functioning and mental health (Gay et al. 2016). Psychologically, exercise has been widely associated with the reduction of depressive symptoms for people with arthritis (Josefsson, Lindwall, and Archer 2013; Neuberger et al. 2007). Physically, exercise is not only beneficial for symptom reduction, but can slow down the progression of the condition (Bennell, Hall, and Hinman 2016). As such, clinical recommendations now suggest that exercise should be included as a treatment option for symptom management for osteoarthritis and as part of physiotherapy for rheumatoid arthritis (NICE 2018a, 2018b; Bennell, Hall, and Hinman 2016). The notion of 'treatment' bears the essential hallmark of exercise is medicine (EiM); a global health initiative promoting physical activity and exercise as fundamental in preventing, managing and treating disease (Lobelo, Stoutenberg, and Hutber 2014). The movement calls on healthcare professionals to prescribe exercise and for patients to take responsibility for their health by becoming more active (Sallis 2015; Berryman 2010). EiM promotes more exercise as good for everyone, but although exercise can be beneficial, there are tensions in the way it is promoted. Namely, Williams et al. (2018) critique EiM in relation to a clinical population of people with spinal cord injury and people with arthritis. They highlight how physical activity guidelines lack specificity for the individual, which can be problematic given the variance in severity of symptoms in chronic illness. Furthermore, EiM provides a blanket statement that more exercise is always good for all, but this arguably is not the case for clinical illness. In addition, by overly promoting exercise for health, Williams et al. (2018) argue it may undermine other motivators for activity, such as for fun and enjoyment. Others have also acknowledged the controversial nature of EiM, specifically Adamson et al. (2018) identified that when exercise was not possible people with multiple sclerosis had feelings of guilt due to a lack of compliance with prescriptions. Too much emphasis on exercise for health can therefore have negative consequences.

Despite the exercise is medicine agenda within clinical practice, people with arthritis are continually reported to be less active than the general population (Murphy et al. 2017). Further, $84 \%$ of adults with arthritis were found to avoid activities such as exercise or sport (Hunter and Riordan 2014). Avoidance of activities can have negative consequences, with a reduction in physical activity associated with an increase in arthritic symptoms such as pain and stiffness (Richardson, Grime, and Ong 2014). Activity restrictions may also limit opportunities to socialise, putting people with arthritis at greater risk of mental distress (Machado, Gignac, and Badley 2008; Richardson, Grime, and Ong 2014). Maintaining a physically active lifestyle can thus be extremely beneficial for people with arthritis. Although all these factors are relevant, it is important to note that the highest rates of inactivity are in people with arthritis who are older, less educated and have poorer levels of psychosocial and physical health (Murphy et al. 2017). To help promote and increase physical activity in this population, it is important to first understand why people with arthritis are inactive.

Existing research has focused on exploring the barriers, facilitators and benefits of physical activity and exercise for people with arthritis (Wilcox et al. 2006; Gyurcsik et al. 2009; Kamwendo, Askenbom, and Wahlgren 1999; van Zanten et al. 2015). A review by van Zanten et al. (2015) found that pain and fatigue are the two most commonly reported arthritis specific barriers to exercise throughout the literature. Other common barriers included stiffness, mobility, a lack of provisions such as arthritis specific exercise programmes, a lack of knowledge about appropriate exercise regimes, and a fear of aggravating the disease. Findings from exercise interventions echo these barriers, highlighting how ill-health such as flare-ups of the condition and exercise induced pain can result in dropout from an exercise programme (Beckwée et al. 2015; Withall et al. 2016). Yet, symptom management, pain relief and distraction, joint function and independence were all cited by van Zanten et al. (2015) as perceived benefits of activity, whereas, support (from a variety of 
sources) and strength and aerobic capacity were viewed as facilitators to exercise. Veldhuijzen van Zanten et al. (2015) argued that there was a clear similarity between the factors cited as barriers and benefits of exercise. For instance, pain and fatigue are the most common barriers, but reductions in pain and fatigue, through symptom management and pain relief, are perceived benefits of exercise. As such, factors that are associated with the physical impairment are largely important for adopting and maintaining a physically active lifestyle. On top of the arthritis specific barriers, people with arthritis also report generic barriers to participation, such as time, motivation, weather and competing responsibilities.

In general, the research literature on barriers, facilitators and benefits of exercise often risks artificially segregating factors at the expense of understanding the process of exercise experiences. Methodologically, many of the studies use surveys or questionnaires to collect data (e.g. Brittain et al. 2011; Gyurcsik et al. 2009; Henchoz, Zufferey, and So 2013; Hutton et al. 2009). This type of method isolates factors from the context in which they are experienced. For example, we know pain is a commonly reported barrier to physical activity, but we do not know how pain occurs (symptomatic or aggravated from exercise) or what other daily activities it may limit. In addition, deductive questionnaires and surveys limit findings to previously identified barriers. On the rare occasions a qualitative approach is used, insights into context and meaning have been constrained by highly structured interview schedules incorporating predominately closed questions (e.g. Fongen, Sveaas, and Dagfinrud 2015). Similarly, Fongen, Sveaas, and Dagfinrud (2015) reduced interview data to a frequency analysis, stating that 45 people report fatigue as a barrier to activity. This quantification limits the understanding about the meaning behind fatigue as a barrier.

In contrast, the use of narrative interviews has helped to better contextualise previously segregated factors (Cartwright et al. 2015; Kaptein et al. 2013; Squire 2012; Stamm et al. 2008, 2009; Stamm et al.2010). Kaptein et al. (2013) discussed how other roles, such as balancing demands of work, can make the decision to be physically active more difficult. For example, people with arthritis make 'trade-offs' as to where to put their energy, such as choosing to clean the house rather than exercise. This adds to our understanding of how commonly reported barriers, such as fatigue and competing responsibilities, can interact and impact on regular exercise (Der Ananian et al. 2008; Wilcox et al. 2006). Equally, making adaptions to daily occupations such as work, home-life and exercise is associated with living-well with rheumatoid arthritis (Squire 2012); suggesting that people who are more able to adapt their physical activity to suit the needs of the condition are more likely to lead more advantageous lives. Nonetheless, this research broadly analyses daily life experiences of people with arthritis, consequently a more focused study on physical activity is needed to develop a deeper theoretical understanding (Squire 2012). Thus, there is a need to specifically address physical activity and arthritis (inflammatory and degenerative), whilst using interpretive methods of inquiry to understand the process and meaning of exercise experiences with arthritis. The present study therefore aims to build on previous research by interpretively exploring experiences of arthritis and physical activity. In this study, the research questions were: (1) how do people with arthritis experience physical activity after illness? and (2) what are the processes that enable or restrict people with arthritis to lead physically active lifestyles?

\section{Methodology}

The present study was driven by an interpretivist paradigm that assumes a relativist ontology, for instance, meaning is subjective and realities are multiple, and a constructionist epistemology, such as we construct our knowledge through interactions with others and knowledge cannot be objectively observed (Creswell 2013). By asking participants to narrate their subjective experience, the multiple versions of reality of living with arthritis and physical activity can be illuminated and explored. 


\section{Sampling and participants}

Ethical approval was granted by the University Ethics Committee prior to a focused recruitment period. A purposive sampling strategy was used to select the most appropriate sample to answer the research question (e.g. selecting participants with a variety of arthritic conditions and physical activity experiences). Recruitment information was distributed to UK-based arthritis charities and through social media. On expressing an interest in participating, the lead researcher confirmed with participants that they were diagnosed with either inflammatory arthritis (e.g. rheumatoid arthritis, ankylosing spondylosis or psoriatic arthritis) or degenerative arthritis (e.g. osteoarthritis). In total, 21 people (6 male, 15 female) participated in the study (see Table 1.) and were aged between 24 and 79 years $(M=57.7)$. As both rheumatoid arthritis and osteoarthritis are most likely to develop over the age of 40 and are more common in women than in men, the sample was considered appropriate for the arthritis population (Carmona et al. 2010; Palazzo et al. 2016). Participants had been diagnosed with arthritis for between 6 months and 35 years $(M=12.7$ years) at the time of the study; by interviewing participants with a range of time since diagnosis, the researcher can address the exercise experiences at different stages after diagnosis and treatment.

\section{Data collection}

Participants engaged in a life-story interview with the lead researcher. The interviews took place at a time and location suitable to the participant and lasted between 55 and $160 \mathrm{~min}(M=102 \mathrm{~min}$ ); a combined total of $35 \mathbf{h}$ of data. The focus of the interviews was for the participant to tell their personal story of arthritis and physical activity. Loosely referring to the interview guide, the researcher emphasised discussion around their physical activity involvement across their lifespan. As Riessman (2008) argues, the researcher must give-up control and allow the participant to lead the interview. For example, during one interview the researcher followed digressions towards stories about family members, which at first seemed unrelated, however became important for understanding the participant's exercise experiences. In addition, questions such as 'tell me a story about being active with arthritis?' or 'can you describe the last time you were physically active?' were used to stimulate descriptive life-story data. Probing questions were also utilised to

Table 1. Participant demographics.

\begin{tabular}{llclc}
\hline Pseudonym & Gender & Age (years) & Type of arthritis & Length of diagnosis (years) \\
\hline Dorothy & Female & 63 & RA & 20 \\
Jasmine & Female & 65 & OA, RA \& PA & 10 \\
William & Male & 72 & OA & 12 \\
Ruth & Female & 79 & OA \& RA & 9 \\
Jessica & Female & 50 & PA & 24 \\
Isabelle & Female & 62 & OA & 7 \\
Linda & Female & 69 & OA & 4 \\
Susan & Female & 52 & RA & 36 \\
Elizabeth & Female & 51 & RA & 13 \\
Teresa & Female & 73 & OA & 8 \\
Dianne & Female & 67 & OA & 7 \\
Valerie & Female & 73 & OA & 3 \\
Wanda & Female & 52 & OA & 9 \\
Tim & Male & 46 & AS & 20 \\
Andrew & Male & 56 & OA & 8 \\
Lawrence & Male & 53 & OA & 13 \\
Claire & Female & 24 & Arthritis in back & 0.5 \\
Richard & Male & 53 & RA & 30 \\
Tammy & Female & 26 & OA & 0.5 \\
Graham & Male & 57 & OA & 15 \\
Victoria & Female & 69 & OA & 5 \\
\hline
\end{tabular}

$\mathrm{RA}=$ Rheumatoid Arthritis; $\mathrm{OA}=$ Osteoarthritis; $\mathrm{PA}=$ Psoriatic Arthritis; $\mathrm{AS}=$ Ankylosing spondylitis. 
encourage rich, detailed explanations. For instance, 'can you describe how that made you feel?' or 'can you expand on that further?'

\section{Analysis}

The present study used an inductive thematic analysis to consider 'what' was being said, with a focus on the content of the stories (Riessman 2008). The process of thematic analysis is reflexive; the researcher moves forward and backwards through several stages of analysis, including: data familiarisation, coding, theme development, revision, naming and writing up (Braun, Clarke, and Weate 2016). During data familiarisation the researcher transcribed the interviews verbatim and read and re-read transcripts, becoming immersed in the data, whilst making general notes in the margins about the meaning of what is being said (e.g. 'negative experience of exercise' or 'learning about arthritis'). This helped to stimulate coding, a process that systematically identifies important topics of interest to the research questions. This process was data driven; inductively analysing the transcripts and coding based on the data, rather than a pre-existing framework (Nowell et al. 2017). For example, the code 'support impact on family' was labelled to the extract: 'the kids coped very well, a lot of support, activities I couldn't do anymore, so friends would take them'. This example portrays the use of semantic coding, closely capturing the content and describing the data. Latent coding was also used to interpret the deeper meaning of the data. For example, the code: 'health deterioration as motivation' was labelled to the following extract: 'I had to have a wheelchair ... I don't want to go back there'. Although the participant does not explicitly indicate they felt motivated, nor do they specify their past health deterioration as a source of motivation, it is reasonable to infer this from the content and the wider context of the interview. Once all transcripts were systematically coded, the researcher moved on to theme development; organising the codes into themes and continuously refining until the themes robustly represent higher-level patterns in the data. These themes were then listed, with the relevant codes underneath, and checked against original data quotes to ensure they robustly represented the titled theme. The second author then acted as a critical friend in developing and refining the themes by critiquing and questioning the structure and content of previously constructed themes. After revising and renaming the themes, the researcher continued the writing up process and returned to the data extracts to ensure each theme was correctly represented. Further refinement of the theme structure and naming was conducted if the extracts no longer fitted within the original thematic framework.

\section{Results and discussion}

The results and discussion have been combined to conceptualise and theorise the reported data instantaneously. Through our inductive thematic analysis of the data we produced three themes; making sense of arthritis, adapting and enjoying exercise, and exercise as medicine. These three themes offer an insight into how people with arthritis can experience physical activity, and the processes which can enable or restrict physically active lifestyles.

\section{Making sense of arthritis}

Through the early stages of arthritis, people go through a period of biographical disruption, in which life is interrupted by symptoms and alterations to daily living (Bury 1982). The unpredictable nature of arthritis can be difficult to understand. For instance, people with arthritis can experience sudden flare-ups which are acute bouts of pain or inflammation, usually with an unknown trigger, causing severe physical limitations (Bingham et al. 2009). Even when illness is expected (i.e. as part of ageing), symptoms can be highly disruptive to the life course and can have a large impact on daily living (Sanders, Donovan, and Dieppe 2002). Thus, we highlight that people with arthritis 
must go through a period of making sense of arthritis to adjust to their symptoms. Developing a greater understanding of arthritis and gaining perceived control of the condition was important to how they experienced exercise. Participants were able to have positive exercise experiences through an ongoing meaning making process that draws on their experiential, social and medical knowledge over time. Participants commonly described pain as one of the most prominent symptoms that they experienced. How participants perceived their pain was a particularly important factor in whether pain hindered physical activity, as one participant stated:

It's not the pain itself that stops me doing it, it's what that pain means and the implications of that pain in the future. So, before I was diagnosed with arthritis, I didn't know what it was, and I hoped that it would get better and that carrying on playing [sport] to a certain extent wouldn't really make it worse, whereas now I know that it is worse, the pain stops me because I think, ok I'm doing some damage and that scares me. [Tammy, 26, OA]

Tammy interpreted pain as a signal that exercise was worsening her arthritis. Previous literature regarding avoidance behaviours suggests that when people perceive pain to be doing harm they avoid certain activities, for instance, their negative beliefs about pain reinforce inactivity (Lööf et al. 2015). If activity levels are reduced this can lead to a negative pain cycle; reduced physical activity leading to increased pain, stiffness and immobility, leading to further inactivity (Kamwendo, Askenbom, and Wahlgren 1999). One participant explained how her evolving interpretations of flare-ups relate to her physical activity:

I realised that the flares are just flares ... you can't control the flares, a flare is a flare, if you flare up it doesn't necessarily mean you have done something, it just means that you have flared, I remember sitting there [doctor's office] thinking I always thought you flared if you had hurt yourself or done too much or over exercised or done this or done that. [Jessica, 50, Psoriatic Arthritis]

Some participants, like Jessica, initially interpreted flare-ups as an indicator of physical overexertion. Fear of exercise causing harm or aggravating the condition is regularly reported as a barrier to physical activity (van Den Berg et al. 2007; Bajwa and Rogers 2007). However, Jessica was able to reflect on her learning process, identifying the doctor's knowledge and advice as stimulus for reinterpretation. Participants discussed how learning about pain, and re-evaluating their perceptions, shaped their experience of exercise.

I might be a bit stiff as anybody is that exercises, but I'm not in pain, and there is a difference, I think there is good pain and bad pain, when you are in bad pain it is the throbbing pain that you can't move away from, and it's there. But the good pain is the pain where you think, yeah OK you hurt but I knew I lifted those weights this morning you know, so it's almost like a badge of honour. [lsabelle, 62, OA]

Isabelle differentiates between pain as a natural consequence of physical exertion $\left(\mathrm{O}^{\prime} \mathrm{Connor}\right.$ and Cook 1999) and symptomatic arthritis pain which is a widely accepted barrier to physical activity (Kaptein et al. 2013; Petursdottir, Arnadottir, and Halldorsdottir 2010). By continually being active, participants can learn to differentiate between types of pain, and the bodies reaction to exercise (Loeppenthin et al. 2014). Similarly, participants who described exercise pain as an achievement rather than a destructive concept, associated themselves more with an exercise identity, stepping away from the suffering of arthritis and embracing their experiences of exercise.

For many participants, engaging with regular exercise was determined by whether their symptoms were managed:

If I wasn't on the medication then that [pain] would go back into complete overdrive and I would get pain in all the joints and I wouldn't be able to move, that's like I was in the beginning, so it is only the medication that is doing a lot of the controlling, but I have to do the rest. [Dorothy, 63, RA]

Dorothy recognised the necessity of medication in controlling arthritis but depicts her perceived responsibility to further help control the condition. Feeling responsible for health can to some extent be beneficial and motivate people to be physically active; however, it can also be 
detrimental when being active becomes unattainable (Guttman and Ressler 2001). Thus, when arthritis is not under control, exercise becomes difficult, as another participant claimed:

It [exercise] has always been a big part, but it isn't now. I can't do anything now at all. As I say I still swim, but not as often as I would like too, but that depends on health and things as well, but also, I say the incontinence hasn't helped, but that is not to do with arthritis, it is to do with the medication ... for the arthritis. [Jasmine, 65, RA, OA \& Psoriatic Arthritis]

Many factors can therefore impact whether exercising is possible, including symptoms and sideeffects of medication. If the condition is not under control, participants have more negative experiences of exercise, or disengage from activity altogether. Thus, although physical activity can be used as a way to take control of life with arthritis by resisting disability and creating a meaningful life (Loeppenthin et al. 2014), it is also important to note that at times exercise is not possible and not suitable. Participants therefore suggested that by developing a better understanding of their arthritis and learning how to control the condition through medication and appropriate rest, they could have more rewarding experiences of physical activity and exercise. For many, this learning process was not in isolation from society and participants highly valued the experience of others in this process:

If you get a first-hand experience, from somebody who is perhaps in the same boat as you, I think then you might take note might you, and think you know if that helped that person then perhaps it can help me.. with the [arthritis charity] if you meet other people, you know, they understand a bit more because they may have had the same experience as you, or you learn from each other really. [Valerie, 73, OA]

It is well documented that vicarious experience can have a positive impact on the person's selfefficacy for physical activity (Warner et al. 2014). Hearing about others' experiences may promote confidence in their ability to perform an activity, alongside giving information and increasing their knowledge about arthritis and exercise. Kaptein et al. (2013) report that having social support in the form of a role model was an important facilitator in staying active with arthritis. Similarly, Richardson, Smith, and Papathomas (2017) suggest that people with disabilities may feel more supported if they have a role model in an exercise environment, and these vicarious experiences can positively shape beliefs about exercising with a disability.

\section{Adapting and enjoying exercise}

To be physically active, participants at times had to make substantial changes to their daily life. For participants who previously exercised, adapting exercise meant making physical changes to their lifestyle to be able to continue without aggravating the condition:

But I always use to love running outdoors, it's so much better for me than being in the gym... I don't find cycling that hard to do, I could just carry on forever, unless you are going up a hill I suppose faster, but it doesn't get you working, I don't get worked up, my body doesn't feel worked cycling as it used to do when I did all of my other exercises, but I am persevering with it. [Andrew, 56, OA]

How participants experienced exercise changed; exercise was at times perceived by participants as restricted to suit the arthritis and lacking enjoyment. Enjoyment of exercise is considered an important factor to be able to maintain engagement with regular exercise (Larkin et al. 2017; Petursdottir, Arnadottir, and Halldorsdottir 2010), and therefore for exercisers, one of the main difficulties to adapting exercise successfully can be interest in continuing the activity (Der Ananian et al. 2006). Similarly, Hunt and Day (2019) identified in a sample with chronic pain that although adapted sport can enable someone to maintain an active lifestyle, it often lacked the fulfilment that their previous sporting involvement once gave them. Thus, it was important for participants to discover enjoyment from adapted exercise, as one participant described:

I have played tennis, well that's a fun exercise to me, whereas swimming I really enjoy it once I'm there, I suppose I enjoy it, I do enjoy it, I love getting in the water and once you start swimming it's a lovely feeling 
and actually I enjoy the yoga once I start, it sort of takes your mind and you concentrate on something, just on that basically, it's free, it makes you relax I suppose and frees your mind and so, yeah sort of is a pleasure. [Valerie, 73, OA]

Affective responses to exercise, such as pleasure or displeasure, are thought to influence motivation. For instance, feelings of enjoyment are considered to be more powerful than knowledge of health benefits for continuing prolonged exercise behaviour (Ekkekakis, Parfitt, and Petruzzello 2011; Dishman, Sallis, and Orenstein 1985). Thus, when participants were able to find an exercise or sport that adapted to their arthritis but was also enjoyable, exercise was considered more sustainable and became a positive experience. Others found it more difficult to gain enjoyment from exercise, as certain elements were seemingly missing from their experience:

Generally, I don't enjoy it [adapted exercise] that much unless it is a lovely walk on the downs. But I really want to get back into my life the enjoyment factor and that's what I'm missing at the moment, so I really want to try and find some sort of team sport or team activity where it is competitive and I'm actually just loving it, because you know when you have an amazing game of football, you are flying ... there is nothing better than when you are playing well and just absolutely buzzing and enjoying it, it's just fantastic, and that's really what l'm missing in my life at the moment, so yeah it has definitely changed since I have been diagnosed. [Tammy, 26, OA]

Tammy described how playing in a team sport could enhance her enjoyment of adapted exercise, but how she is yet to find this since having arthritis. The social benefits of exercising in groups have been widely reported, not only for adherence to an exercise regime (Kang et al. 2007; Schoster et al. 2005) but as a buffering effect against symptoms such as pain (Zimmer, Hickey, and Searle 1995). Another participant also suggested how social support impacted positively on his gym experience:

Actually, there is a lot of people who if you go to the gym, you know they understand. If something is wrong and they will help you and they will give you the incentive and motivation to work through it and you know you build up a new social life and that sort of drags you into it and then you want to go more. [Richard, 53, RA]

Richard built a new social group through being active, he believed that this helped to motivate him to continue; 'dragging' him into the exercise world. Thus, support from others is more than direct encouragement or guidance; the act of social inclusion and being part of a group identity may be more important for maintaining exercise involvement over a longer period of time (Loeppenthin et al. 2014). Participants also discussed how their wellness improved by socialising with others through exercise, as one participant added:

You have that pleasure of feeling like you belong to something. Because most of the time you don't feel like you belong in the human race, you feel a bit, umm, you just don't feel like you can join in, so you don't feel like you are part of it anymore. [Jasmine, 65, RA, OA \& Psoriatic Arthritis]

Living with a chronic condition, such as arthritis, can increase social isolation by compromising the autonomy of the individual (Mackichan, Adamson, and Gooberman-Hill 2013). However, exercise can facilitate greater social inclusion and bring pleasure into their life by increasing contact with others and helping people with arthritis feel more included within society.

\section{Exercise as medicine}

Exercise has been shown to have health and medicinal benefits for people with arthritis (Bennell, Hall, and Hinman 2016; Gay et al. 2016). The role of exercise for some was to improve health and arthritic symptoms:

It's my health, I just want to, I just want to keep going because I have realised ... my health has improved since the op, it has improved and that's what is motivating me, I don't want to lose it, I want it to get better. [Elizabeth, 51, RA] 
Most participants identified how they experienced physical and/or mental health benefits of exercise, suggesting it held medicinal qualities for them. Most people recognise that exercise is good for your health, but experiencing health benefits first-hand can reinforce motivation for exercisers to maintain regular activity (Wilcox et al. 2006).

For some, exercise even became an alternative option to medication, as another participant explained:

I thought well actually I'm going downhill and I have to start to go see the doctor again to try and see if he has got anything new for me, but that's not the way out of here, I don't want the medication, and so I forced myself into the gym. [Richard, 53, RA]

Although health may be an initial reason to adopt a physically active lifestyle, or new exercise regime, this was not always perceived positively and at times exercise became a chore, as one participant described:

I always make sure it is in my diary and it is my time and it has to be something fairly major that will stop me going to it. So, it is high priority and probably non-negotiable, there was a time when, anybody could have said "oh would you like a coffee on Monday morning" and I would have gone "YES!" but I have changed my attitude ... I have tried to make myself not feel negative about having to do the exercise. At first, I did, at first, I felt angry and resentful because you know, very much poor me, I have been through all this and now I have to do this as well, and ... so there was a feeling of resentment ... another burden that I had to do. [lsabelle, 62, OA]

When participants thought of exercise as something they 'have to do', something they should be doing for their health, it became a burden in their life. It is argued that when exercise is framed in terms of health, rather than fun or enjoyment, it can supress the later, changing the way people experience exercise (Werle, Wansink, and Payne 2015). Critically, this may be exaggerated for people with disabilities as there is an overt focus on the specific health benefits of exercise, ignoring and stifling other possibilities of exercise experiences (Williams et al. 2018). Thus, when participants perceived exercise as a burden it was said to make it more difficult to persevere with an exercise regime. Participants spoke of how they needed to change their attitude towards exercise in order to maintain an active lifestyle and feel more positive towards being active.

Attitudes and perceptions towards exercise and understanding how to exercise may also be impacted by the way healthcare professionals discuss physical activity with the patient, as one participant described:

When you are sporty, they [doctors] generally just don't really get it. I think they just kind of say just stop doing this ... but it's like I need more than that, I need "this is what I can do, this is what I can't do, this is what is going to happen" ... so basically kind of said "don't do this and don't do that" but they haven't really said "but do this and do that". [Tammy, 26, OA]

A lack of professional support is regularly reported as a barrier to activity (e.g. Wilcox et al. 2006; Veldhuijzen van Zanten et al. 2015), however our participants' experiences portray that support not only needs to be given but must be better tailored to the individual. Although participants' received support, at times healthcare professionals (e.g. doctors or physiotherapists) were said to have a blinkered approach, preferring to offer surgery over exercise management. Research has demonstrated that patients with arthritis are less likely to engage in regular exercise if they do not discuss it with their rheumatologist (Iversen, Eaton, and Daltroy 2004). Therefore, it is important for healthcare professionals to address exercise and combat possible negative beliefs (Larkin et al. 2017). By reinforcing to patients what they cannot do this may emphasise a negative stigma towards arthritis and physical activity.

\section{Conclusions}

This study is one of few studies to qualitatively explore physical activity and arthritis (see also, Kaptein et al. 2013; Loeppenthin et al. 2014). We have offered unique insights into how people 
living with arthritis experience physical activity after illness and the processes that are involved in trying to fulfil a physically active lifestyle. First, our findings suggest exercise is experienced as part of a larger ongoing meaning-making process that participants go through in an effort to live better with arthritis. In the early phases of the illness, participants tried to make sense of new and unpredictable symptoms, and exercise often assumed secondary importance compared to adapting to chronic illness. Later, after living with and learning about the illness, participants perceived they had greater control over arthritis and were better able to engage with exercise in a positive way. Second, enjoyment of exercise was important to participants as they tried to find pleasure in exercising. The social dimension of exercise gave many participants pleasure, providing a sense of belonging. Although preserving health and wellbeing was almost always constructed as a motivating factor in the pursuit of physical activity; participants connected an exclusive health focus to negative emotions and resentment towards exercising.

Our analysis presents several important considerations for effective physical activity promotion for people living with arthritis. First, making sense of a life-changing chronic illness is a difficult process that cannot be isolated from efforts to get people more active. It is well-known that arthritis can be a detrimental interruption to the expected life course which demands a focused period of adjustment and acceptance (Bury 1982; Cartwright et al. 2015). As the body changes due to illness it will go through fluctuations in bodily sensations, such as stiffness, joint pain, and fatigue, over time but also on a daily basis. As Phoenix and Bell (2018) state in relation to an ageing population, these fluctuations interrupt and often compromise a person's capacity or inclination to be physically active. Exercise promotion, or indeed prescription, must therefore be sensitive to the demands of adapting to a new life, an ongoing, dynamic process (Grønning et al. 2011). In fact, physical activity promotion should purposefully address this transitional period rather than provide an exclusive focus on exercise motivation and behaviour. For instance, a more holistic early intervention to promote exercise might include educational sessions on living with arthritis symptoms such as, pain, fatigue and stiffness without any explicit reference to exercise. Although not focusing on exercise may appear counterintuitive, if adaptation to arthritis must occur before exercise can be enjoyed, it makes sense for exercise promotion to support this process first and hopefully accelerate it. As the intervention progresses towards more exercisespecific information, healthcare professionals would do well to maintain the holistic approach via more patient-centred efforts (e.g. Williams et al. 2018). For example, discussing with the patient their adaptations to daily tasks, how they are coping with the condition, and their perceptions of exercise, will help both parties gauge the type of physical activity/exercise appropriate for that person. This study suggests that if a patient is still processing the changes associated with chronic illness, then it may be ineffective to over-prescribe exercise at this time, as it may contribute to negative exercise experiences and long-term disengagement. Understanding the relationship between physical activity and biographical disruption due to arthritis is an area for future research. Utilising life-history or biographical interviews to contextualise stories within the broader life history would support this future research direction; developing understanding of the meaning making of the body before arthritis and through the illness transition (Coles and Knowles 2001; Smith and Sparkes 2016). Furthermore, analysing the data through the means of narrative analysis would be beneficial, as it would help forge connections between the past, present and future (Riessman 2005). How people story their lives through the transition into illness can impact coping and therefore the likelihood of exercise engagement (see Papathomas, Williams, and Smith 2015).

The value placed on exercise enjoyment and social benefits also challenges the way exercise is traditionally prescribed for arthritis. For example, most public health messaging frames exercise as a means to manage arthritis symptoms, alleviate pain and improve health and wellbeing (Public Health England 2014; Athritis Research UK 2017). References to pleasure and social engagement are conspicuous by their absence and are not a part of the broader exercise is medicine narrative. Finding ways to integrate pleasure across all phases of exercise prescription is an important next step for those seeking to increase exercise in arthritis populations. 
Echoing suggestions from past research (e.g. Kamwendo, Askenbom, and Wahlgren 1999; Williams et al. 2018), healthcare professionals should guide patients to participate in activities that are fun and emphasise the importance of enjoyment and meaningful activities as well as the health benefits it provides. Particularly, this study suggests that encouraging activities that involve social interaction, would for some be an effective way of increasing pleasure in exercise. Although a focus of enjoyment is warranted, if no health benefits are being experienced by the patient, or worse it is having a negative impact on pain, this could be detrimental to the their condition and exercise motivation. Thus, healthcare professionals must try to guide patients towards exercise that brings both enjoyment and health benefits. Balancing exercise for pleasure with exercise for health is a delicate, personal process and healthcare professionals must tailor their exercise recommendations if they are to achieve it.

\section{Acknowledgments}

We would like to thank the arthritis charities and groups that were involved in participant recruitment for their ongoing support with this research. Thanks also go to all the participants involved in this study for their willingness and openness to be interviewed, the research would not be possible without them.

\section{Disclosure statement}

No potential conflict of interest was reported by the authors.

\section{Funding}

No funding has been received for this work.

\section{Notes on contributors}

Emily R. Hunt is a Lecturer in Sport, Health and Exercise Sciences (Psychology) within Brunel University London's College of Health and Life Sciences, and a PhD candidate in Sport and Exercise Psychology within Loughborough University's School of Sport, Exercise and Health Sciences. Her thesis explores the use of narratives for behaviour change, focusing on an arthritic population.

Anthony Papathomas is a Lecturer in Sport and Exercise Psychology within Loughborough University's School of Sport, Exercise and Health Sciences. His research deploys qualitative methodologies to explore the experiences of marginalised groups and clinical populations.

\section{References}

Adamson, B. C., M. D. Adamson, M. M. Littlefield, and R. W. Motl. 2018. "'Move It or Lose It': Perceptions of the Impact of Physical Activity on Multiple Sclerosis Symptoms, Relapse and Disability Identity." Qualitative Research in Sport, Exercise and Health 10 (4): 457-475. doi:10.1080/2159676X.2017.1415221.

Athritis Research UK. 2017. "Providing Physical Activity Interventions for People with Musculoskeletal Conditions." Arthritis Research UK; Department of Health; Public Health England; NHS England. http://www.arthritisresearchuk. org/ /media/Files/Policyfiles/Reports/physical-activity-and-MSK-health-report.ashx?la=en

Bajwa, H. A., and L. Q. Rogers. 2007. "Physical Activity Barriers and Program Preferences among Indigent Internal Medicine Patients with Arthritis." Rehabilitation Nursing 32 (1): 31-34. doi:10.1002/j.2048-7940.2007.tb00146.x.

Beckwée, D., I. Bautmans, T. Scheerlinck, and P. Vaes. 2015. "Exercise in Knee Osteoarthritis - Preliminary Findings: Exercise-Induced Pain and Health Status Differs between Drop-Outs and Retainers." Experimental Gerontology 72: 29-37. doi:10.1016/j.exger.2015.09.009.

Bennell, K. L., M. Hall, and R. S. Hinman. 2016. "Osteoarthritis Year in Review 2015: Rehabilitation and Outcomes." Osteoarthritis and Cartilage 24 (1): 58-70. doi:10.1016/j.joca.2015.07.028.

Berryman, J. W. 2010. "Exercise Is Medicine: A Historical Perspective." Current Sports Medicine Reports 9 (4): $195-201$. doi:10.1249/JSR.0b013e3181e7d86d. 
Bingham, C. O., C. Pohl, T. G. Woodworth, S. E. Hewlett, J. E. May, M. U. Rahman, J. P. Witter, et al. 2009. “Developing a Standardized Definition for Disease 'Flare'; in Rheumatoid Arthritis (OMERACT 9 Special Interest Group)." The Journal of Rheumatology 36 (10): 2335-2341. doi:10.3899/jrheum.090369.

Bolen, J., L. Schieb, J. M. Hootman, C. G. Helmick, K. Theis, L. B. Murphy, and G. Langmaid. 2010. “Differences in the Prevalence and Impact of Arthritis among Racial/Ethnic Groups in the United States, National Health Interview Survey, 2002, 2003, and 2006." Preventing Chronic Disease 7 (3): 1-5. http://www.cdc.gov/pcd/issues/2010/may/10_ 0035.htm

Bookwala, J., T. L. Harralson, and P. A. Parmelee. 2003. "Effects of Pain on Functioning and Well-Being in Older Adults with Osteoarthritis of the Knee." Psychology and Aging 18 (4): 844-850. doi:10.1037/0882-7974.18.4.844.

Brittain, D. R., N. C. Gyurcsik, M. McElroy, and S. A. Hillard. 2011. "General and Arthritis-Specific Barriers to Moderate Physical Activity in Women with Arthritis." Women's Health Issues 21 (1): 57-63. doi:10.1016/j.whi.2010.07.010.

Bury, M. 1982. "Chronic Illness as Biographical Disruption." Sociology of Health \& Illness 4 (2): 167-182. doi:10.1111/ 1467-9566.ep11339939.

Carmona, L., M. Cross, B. Williams, M. Lassere, and L. March. 2010. "Rheumatoid Arthritis." Best Practice and Research: Clinical Rheumatology 24 (6): 733-745. doi:10.1016/j.berh.2010.10.001.

Cartwright, T., E. Fraser, S. Edmunds, N. Wilkinson, and K. Jacobs. 2015. "Journeys of Adjustment: The Experiences of Adolescents Living with Juvenile Idiopathic Arthritis." Child: Care, Health and Development 41 (5): $734-743$. doi: $10.1111 /$ cch.12206.

Coles, A., and G. Knowles. 2001. Lives in Context: The Art of Life History Research. Oxford: Alta Mira Press.

Creswell, J. W. 2013. Qualitative Inquiry \& Research Design: Choosing among Five Approaches. Thousand Oaks, CA: SAGE Publications.

Der Ananian, C., S. Wilcox, R. Saunders, K. Watkins, and A. E. Evans. 2006. "Factors that Influence Exercise among Adults with Arthritis in Three Activity Levels." Preventing Chronic Disease 3 (3): 1-16. www.cdc.gov/pcd/issues/2006/jul/05_ 0220.htm

Der Ananian, C., S. Wilcox, K. Watkins, R. Saunders, and A. E. Evans. 2008. "Factors Associated with Exercise Participation in Adults with Arthritis." Journal of Aging and Physical Activity 16 (2): 125-143. http://www.ncbi.nlm. nih.gov/pubmed/18483438

Dishman, R. K., J. F. Sallis, and D. R. Orenstein. 1985. "The Determinants of Physical Activity and Exercise." Public Health Reports 100 (2): 158-171. https://www.ncbi.nlm.nih.gov/pmc/articles/PMC1424729/

Ekkekakis, P., G. Parfitt, and S. J. Petruzzello. 2011. "The Pleasure and Displeasure People Feel When They Exercise at Different Intensities." Sports Medicine 41 (8): 641-671. doi:10.2165/11590680-000000000-00000.

Fongen, C., S. H. Sveaas, and H. Dagfinrud. 2015. "Barriers and Facilitators for Being Physically Active in Patients with Ankylosing Spondylitis: A Cross-Sectional Comparative Study." Musculoskeletal Care 13 (2): 76-83. doi:10.1002/ msc. 1088 .

Gay, C., A. Chabaud, E. Guilley, and E. Coudeyre. 2016. "Educating Patients about the Benefits of Physical Activity and Exercise for Their Hip and Knee Osteoarthritis. Systematic Literature Review." Annals of Physical and Rehabilitation Medicine 59 (3): 174-183. doi:10.1016/j.rehab.2016.02.005.

Gettings, L. 2010. "Psychological Well-Being in Rheumatoid Arthritis: A Review of the Literature." Musculoskeletal Care 8 (2): 99-106. doi:10.1002/msc.171.

Grønning, K., B. Lomundal, H. S. Koksvik, and A. Steinsbekk. 2011. "Coping with Arthritis Is Experienced as A Dynamic Balancing Process. A Qualitative Study." Clinical Rheumatology 30 (11): 1425-1432. doi:10.1007/s10067-011-1836-9.

Guttman, N., and W. H. Ressler. 2001. "On Being Responsible: Ethical Issues in Appeals to Personal Responsibility in Health Campaigns." Journal of Health Communication 6 (2): 117-136. doi:10.1080/10810730116864.

Gyurcsik, N. C., L. R. Brawley, K. S. Spink, D. R. Brittain, D. L. Fuller, and K. Chad. 2009. "Physical Activity in Women with Arthritis: Examining Perceived Barriers and Self-Regulatory Efficacy to Cope." Arthritis Care and Research 61 (8): 1087-1094. doi:10.1002/art.24697.

Henchoz, Y., P. Zufferey, and A. So. 2013. "Stages of Change, Barriers, Benefits, and Preferences for Exercise in RA Patients: A Cross-Sectional Study." Scandinavian Journal of Rheumatology 42 (2): 136-145. doi:10.3109/ 03009742.2012.724707.

Hughes, D. 2009. "Osteoarthritis and Inflammatory Arthritis." Surgery 27 (2): 75-79. doi:10.1016/j.mpsur.2008.12.013.

Hunt, E. R., and M. C. Day. 2019. "Narratives of Chronic Pain in Sport." Journal of Clinical Sport Psychology 13 (1): 1-16. doi:10.1123/jcsp.2017-0003.

Hunter, D. J., and E. A. Riordan. 2014. "The Impact of Arthritis on Pain and Quality of Life: An Australian Survey." International Journal of Rheumatic Diseases 17 (2): 149-155. doi:10.1111/1756-185X.12232.

Hutton, I., G. Gamble, G. Mclean, H. Butcher, P. Gow, and N. Dalbeth. 2009. "Obstacles to Action in Arthritis: A Community Case-Control Study." International Journal of Rheumatic Diseases 12 (2): 107-117. doi:10.1111/j.1756185X.2009.01392.x.

Iversen, M. D., H. M. Eaton, and L. H. Daltroy. 2004. "How Rheumatologists and Patients with Rheumatoid Arthritis Discuss Exercise and the Influence of Discussions on Exercise Prescriptions." Arthritis Care \& Research 51 (1): 63-72. doi:10.1002/art.20168. 
Josefsson, T., M. Lindwall, and T. Archer. 2013. "Physical Exercise Intervention in Depressive Disorders: Meta-Analysis and Systematic Review." Scandinavian Journal of Medicine \& Science in Sports 1-14. doi:10.1111/sms.12050.

Kamwendo, K., M. Askenbom, and C. Wahlgren. 1999. "Physical Activity in the Life of the Patient with Rheumatoid Arthritis." Physiotherapy Research International 4 (4): 278-292. doi:10.1002/pri.174.

Kang, H. S., C. E. Ferrans, M. J. Kim, J. I. Kim, and E.-O. Lee. 2007. "Aquatic Exercise in Older Korean Women with Arthritis: Identifying Barriers to and Facilitators of Long-Term Adherence." Journal of Gerontological Nursing 33 (7): 48-56. http://www.ncbi.nlm.nih.gov/pubmed/17672168

Kaptein, S. A., C. L. Backman, E. M. Badley, D. E. Diane Lacaille, C. H. Beaton, and M. A. M. Gignac. 2013. "Choosing Where to Put Your Energy: A Qualitative Analysis of the Role of Physical Activity in the Lives of Working Adults with Arthritis." Arthritis Care and Research 65 (7): 1070-1076. doi:10.1002/acr.21957.

Larkin, L., S. Gallagher, A. Fraser, and N. Kennedy. 2017. "If a Joint Is Hot It's Not the Time: Health Professionals' Views on Developing an Intervention to Promote Physical Activity in Rheumatoid Arthritis." Disability and Rehabilitation 39 (11): 1106-1113. doi:10.1080/09638288.2016.1180548.

Larkin, L., N. Kennedy, A. Fraser, and S. Gallagher. 2017. "'It Might Hurt, but Still Its Good: People with Rheumatoid Arthritis Beliefs and Expectations about Physical Activity Interventions." Journal of Health Psychology 22 (13): 16781690. doi:10.1177/1359105316633286.

Lobelo, F., M. Stoutenberg, and A. Hutber. 2014. "The Exercise Is Medicine Global Health Initiative: A 2014 Update." British Journal of Sports Medicine 48: 1627-1633. doi:10.1136/bjsports-2013-093080.

Loeppenthin, K., B. A. Esbensen, M. Ostergaard, P. Jennum, T. Thomsen, and J. Midtgaard. 2014. "Physical Activity Maintenance in Patients with Rheumatoid Arthritis: A Qualitative Study." Clinical Rehabilitation 28 (283): $289-299$. doi:10.1177/0269215513501526.

Lööf, H., I. Demmelmaier, E. Welin Henriksson, S. Lindblad, B. Nordgren, C. H. Opava, and U.-B. Johansson. 2015. “FearAvoidance Beliefs about Physical Activity in Adults with Rheumatoid Arthritis." Scandinavian Journal of Rheumatology 44 (2): 93-99. doi:10.3109/03009742.2014.932432.

Machado, G. P. M., M. A. M. Gignac, and E. M. Badley. 2008. "Participation Restrictions among Older Adults with Osteoarthritis: A Mediated Model of Physical Symptoms, Activity Limitations, and Depression." Arthritis Care and Research 59 (1): 129-135. doi:10.1002/art.23259.

Mackichan, F., J. Adamson, and R. Gooberman-Hill. 2013. "'Living within Your Limits': Activity Restriction in Older People Experiencing Chronic Pain." Age and Ageing 42 (6): 702-708. doi:10.1093/ageing/aft119.

Michaud, K., and F. Wolfe. 2007. "Comorbidities in Rheumatoid Arthritis." Best Practice \& Research Clinical Rheumatology 21 (5): 885-906. doi:10.1016/j.berh.2007.06.002.

Murphy, L. B., J. M. Hootman, M. A. Boring, S. A. Carlson, J. Qin, K. E. Barbour, T. J. Brady, and C. G. Helmick. 2017. "Leisure Time Physical Activity Among U.S. Adults With Arthritis, 2008-2015." American Journal of Preventive Medicine 53 (3): 345-354. doi:10.1016/j.amepre.2017.03.017.

Neuberger, G. B., L. S. Aaronson, B. Gajewski, S. E. Embretson, P. E. Cagle, J. K. Loudon, and P. A. Miller. 2007. "Predictors of Exercise and Effects of Exercise on Symptoms, Function, Aerobic Fitness, and Disease Outcomes of Rheumatoid Arthritis." Arthritis and Rheumatism 57 (6): 943-952. doi:10.1002/art.22903.

NICE (National Institute for Health and Care Excellence). 2018a. "Management of Osteoarthritis." NICE Pathways. http:// pathways.nice.org.uk/pathways/osteoarthritis

NICE (National Institute for Health and Care Excellence). 2018b. "Managing Rheumatoid Arthritis." NICE Pathways. http://pathways.nice.org.uk/pathways/rheumatoid-arthritis

Nowell, L. S., J. M. Norris, D. E. White, and N. J. Moules. 2017. "Thematic Analysis: Striving to Meet the Trustworthiness Criteria." International Journal of Qualitative Methods 16 (1): 1-13. doi:10.1177/1609406917733847.

O'Connor, P. J., and D. B. Cook. 1999. "Exercise and Pain: The Neurobiology, Measurement, and Laboratory Study of Pain in Relation to Exercise in Humans." Exercise and Sport Sciences Reviews 27 (1): 119-166. https://journals.Iww. com/acsm-essr/Citation/1999/00270/5_Exercise_and_Pain_The_Neurobiology,.7.aspx

Palazzo, C., C. Nguyen, M. M. Lefevre-Colau, F. Rannou, and S. Poiraudeau. 2016. "Risk Factors and Burden of Osteoarthritis." Annals of Physical and Rehabilitation Medicine 59 (3): 134-138. doi:10.1016/j.rehab.2016.01.006.

Papathomas, A., T. L. Williams, and B. Smith. 2015. "Understanding Physical Activity Participation in Spinal Cord Injured Populations: Three Narrative Types for Consideration." International Journal of Qualitative Studies on Health and Well-Being 10: 1-12. doi:10.3402/qhw.v10.27295.

Petursdottir, U., S. A. Arnadottir, and S. Halldorsdottir. 2010. "Facilitators and Barriers to Exercising among People with Osteoarthritis: A Phenomenological Study." Physical Therapy 90 (7): 1014-1025. doi:10.2522/ptj.20090217.

Phoenix, C., and S. L. Bell. 2018. "Beyond "Move More": Feeling the Rhythms of Physical Activity in Mid and Later-Life." Social Science \& Medicine. doi:10.1016/j.socscimed.2018.05.006.

Public Health England. 2014. "Everybody Active, Every Day. An Evidence-Based Approach to Physical Activity." Public Health England. https://www.gov.uk/government/uploads/system/uploads/attachment_data/file/374914/ Framework_13.pdf

Richardson, E. V., B. Smith, and A. Papathomas. 2017. "Disability and the Gym: Experiences, Barriers and Facilitators of Gym Use for Individuals with Physical Disabilities." Disability and Rehabilitation 39 (19): 1950-1957. doi:10.1080/ 09638288.2016 .1213893$. 
Richardson, J. C., J. C. Grime, and B. N. Ong. 2014. "'Keeping Going': Chronic Joint Pain in Older People Who Describe Their Health as Good." Ageing and Society 34 (08): 1380-1396. doi:10.1017/S0144686X13000226.

Riessman, C. K. 2005. "Narrative Analysis." In Narrative, Memory \& Everyday Life, edited by N. Kelly, C. Horrocks, K. Milnes, B. Roberts, and D. Robinson, 1-7. Huddersfield: University of Huddersfield.

Riessman, C. K. 2008. Narrative Methods for the Human Sciences. Thousand Oaks, CA: SAGE Publications.

Sallis, R. 2015. "Exercise Is Medicine: A Call to Action for Physicians to Assess and Prescribe Exercise." Physician and Sportsmedicine 43 (1): 22-26. doi:10.1080/00913847.2015.1001938.

Sanders, C., J. Donovan, and P. Dieppe. 2002. "The Significance and Consequences of Having Painful and Disabled Joints in Older Age: Co-Existing Accounts of Normal and Disrupted Biographies." Sociology of Health and IIIness 24 (2): 227-253. doi:10.1111/1467-9566.00292.

Schoster, B., L. F. Callahan, A. Meier, T. Mielenz, and D. Lisa. 2005. "The People with Arthritis Can Exercise (PACE) Program: A Qualitative Evaluation of Participant Satisfaction." Preventing Chronic Disease 2 (3): 1-11. http://www. cdc.gov/pcd/issues/2005/jul/05_0009.htm

Smith, B., and A. C. Sparkes. 2016. "Interviews: Qualitative Interviewing in the Sport and Exercise Sciences." In Routledge Handbook of Qualitative Research in Sport and Exercise, edited by B. Smith and A. C. Sparkes, 191-205. London: Routledge.

Squire, R. 2012. "Living Well with Rheumatoid Arthritis." Musculoskeletal Care 10 (3): 127-134. doi:10.1002/msc.1004.

Stamm, T., L. Lovelock, G. Stew, V. Nell, J. Smolen, K. Machold, H. Jonsson, and G. Sadlo. 2009. "I Have A Disease but I Am Not III: A Narrative Study of Occupational Balance in People with Rheumatoid Arthritis." OTJR: Occupation, Participation, Health 29 (1): 32-39. doi:10.3928/15394492-20090101-05.

Stamm, T. A., L. Lovelock, G. Stew, V. Nell, J. Smolen, H. Jonsson, G. Sadlo, and K. Machold. 2008. "I Have Mastered the Challenge of Living with a Chronic Disease: Life Stories of People with Rheumatoid Arthritis." Qualitative Health Research 18 (5): 658-669. doi:10.1177/1049732308316348.

Stamm, T. A., K. P. Machold, J. Smolen, and B. Prodinger. 2010. "Life Stories of People with Rheumatoid Arthritis Who Retired Early: How Gender and Other Contextual Factors Shaped Their Everyday Activities, Including Paid Work." Musculoskeletal Care 8 (2): 78-86. doi:10.1002/msc.168.

Theis, K. A., L. Murphy, J. M. Hootman, C. G. Helmick, and E. Yelin. 2007. "Prevalence and Correlates of ArthritisAttributable Work Limitation in the US Population among Persons Ages 18-64: 2002 National Health Interview Survey Data." Arthritis Care and Research 57 (3): 355-363. doi:10.1002/art.22622.

van Den Berg, M. H., I. G. de Boer, S. le Cessie, F. C. Breedveld, P. M. Theodora, and V. Vlieland. 2007. "Most People with Rheumatoid Arthritis Undertake Leisure-Time Physical Activity and Exercise in the Netherlands: An Observational Study." Australian Journal of Physiotherapy 53 (2): 113-118. doi:10.1016/S0004-9514(07)70044-2.

van Zanten, V., J. C. S. Jet, P. C. Rouse, E. D. Hale, N. Ntoumanis, G. S. Metsios, J. L. Duda, and G. D. Kitas. 2015. "Perceived Barriers, Facilitators and Benefits for Regular Physical Activity and Exercise in Patients with Rheumatoid Arthritis: A Review of the Literature." Sports Medicine 45 (10): 1401-1412. doi:10.1007/s40279-015-0363-2.

Virginia., B., V. Clarke, and P. Weate. 2016. "Using Thematic Analysis in Sport and Exercise Research." In Routledge Handbook of Qualitative Research in Sport and Exercise, edited by B. Smith and A. C. Sparkes, 191-205. London: Routledge.

Vos, T., R. M. Barber, B. Bell, A. Bertozzi-Villa, S. Biryukov, I. Bolliger, F. Charlson, et al. 2015. "Global, Regional, and National Incidence, Prevalence, and Years Lived with Disability for 301 Acute and Chronic Diseases and Injuries in 188 Countries, 1990-2013: A Systematic Analysis for the Global Burden of Disease Study 2013." The Lancet 386 (9995): 743-800. doi:10.1016/S0140-6736(15)60692-4.

Warner, L. M., J. K. Benjamin Schüz, L. P. Wolff, S. Wurm, and R. Schwarzer. 2014. "Sources of Self-Efficacy for Physical Activity." Health Psychology 33 (11): 11298-11308. doi:10.1037/hea0000085.

Werle, C. O. C., B. Wansink, and C. R. Payne. 2015. "Is It Fun or Exercise? the Framing of Physical Activity Biases Subsequent Snacking." Marketing Letters 26 (4): 691-702. doi:10.1007/s11002-014-9301-6.

Wilcox, S., C. Der Ananian, J. Abbott, J. E. Vrazel, C. Ramsey, P. A. Sharpe, and T. Brady. 2006. "Perceived Exercise Barriers, Enablers, and Benefits among Exercising and Nonexercising Adults with Arthritis: Results from a Qualitative Study." Arthritis Care and Research 55 (4): 616-627. doi:10.1002/art.22098.

Williams, T. L., E. R. Hunt, A. Papathomas, and B. Smith. 2018. "Exercise Is Medicine? Most of the Time for Most; but Not Always for All." Qualitative Research in Sport, Exercise and Health 10 (4): 441-456. doi:10.1080/ 2159676X.2017.1405363.

Withall, J., A. M. Haase, N. E. Walsh, A. Young, and F. Cramp. 2016. "Physical Activity Engagement in Early Rheumatoid Arthritis: A Qualitative Study to Inform Intervention Development." Physiotherapy 102 (3): 264-271. doi:10.1016/j. physio.2015.07.002.

Zimmer, Z., T. Hickey, and M. S. Searle. 1995. "Activity Participation and Well-Being among Older People with Arthritis." The Gerontologist 35 (4): 463-471. doi:10.1093/geront/35.4.463.

Zyrianova, Y., B. D. Kelly, J. Sheehan, C. McCarthy, and T. G. Dinan. 2011. "The Psychological Impact of Arthritis: The Effects of Illness Perception and Coping." Irish Journal of Medical Science 180 (1): 203-210. doi:10.1007/s11845-010-0522-2. 